\title{
Accuracy of SARS-CoV-2 molecular laboratory testing: insight on recurrence infection and the new emergent strains
}

\author{
Huda Hassan Al-Griw \\ Department of Microbiology and Parasitology, Faculty of veterinary medicine \\ University of Tripoli, Libya \\ huda_algriw@hotmail.com
}




\section{Current Research in Microbiology and Infection (CRMI)}

Journal Homepage: https://www.refaad.com/views/CRMI/home.aspx

www.refaad.com

2709-7196 (Online) 2709-7188 (Print)

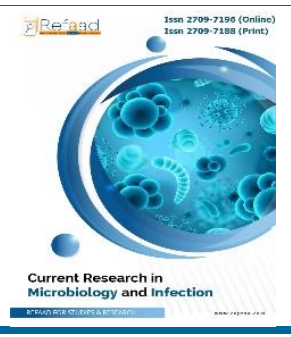

\section{Accuracy of SARS-CoV-2 molecular laboratory testing: insight on recurrence infection and the new emergent strains}

\section{Huda Hassan Al-Griw*}

Department of Microbiology and Parasitology, Faculty of veterinary medicine, University of Tripoli, Libya huda_algriw@hotmail.com

Received: 18/3/2021 Revised: 15/5/2021 Accepted: 5/6/2021 DOI: https://doi.org/10.31559/CRMI2021.2.1.2

\section{Abstract:}

The rapid spread of the SARS-CoV-2 virus and increased number of deaths urged the world to provide accurate diagnostic procedures and apply the correct prevention measures to eradicate the disease. Molecular assays are designed to test the presence of virus RNA. The assays have wanting accuracy represented by false positive and false negative results, in particularly with continuous emerging of SARSCoV-2 genetic variability. Miss interpretation of the test results can lead to bad outcomes for both individuals and the surrounding community when assuming the test is perfect. This review provides an update of the currently available molecular laboratory methods and address the effect of ongoing SARSCoV-2 genetic variability on the performance of RT-PCR, the problem of re-positive test result in recovered patients and provides elements to be considered for performing SARS-CoV-2 test and interpreting the test results.

Keywords: SARS-CoV-2; PCR; LAMP; re-current infection; Point of care.

\footnotetext{
* Corresponding Author

Huda Hassan Al-Griw

Department of Microbiology and Parasitology, Faculty of veterinary medicine, University of Tripoli, Libya

E-mail: huda_algriw@hotmail.com
} 


\section{Introduction}

Since late 2019, the world is facing the biggest challenge to provide sooner and accurate diagnostic procedures, treatments, and apply the correct prevention measures to eradicate the disease. Many diagnostic techniques for corona SARS-CoV-2 are available so far. Molecular assays which directly tests for the presence of active viral RNA (Kucirka et al.). Although there is a heavy reliance on this type of testing for the detection of current infection, scientists know that testing of a coronavirus as a new emerged disease would carry lots of complications. Molecular testing has wanting accuracy represented by false positive (FP) and false negative (FN) results. A false positive occurs when a test result indicates infection, but the person has not actually been infected. A false negative occurs when a test result indicates no infection, but the person in the reality is infected (Manski, 2020). The urgent needs and the racing of the scientists to produce more tests for detection and identification of the virus to be able to implement in local laboratories in short time manner during the course of the outbreak, limited comprehensive validation and evaluation of the developed assays (Pfefferle et al., 2020). Moreover, the continuous alteration in the viral genome added another problem for the accuracy of the implemented assays (Burton et al., 2017, Yu et al., 2020).

This article provides an overview of different types of molecular testing including the recent molecular approaches under validation in clinical set that have been received particular interest for using as point of care purposes, addresses the effect of ongoing SARS-CoV-2 genetic variability on performance of RT-PCR and the problem of repositive test result in recovered patients and provides elements to be considered for accurate SARS-CoV-2 testing.

\section{An update on Molecular Diagnostic Testing for $S A R S-C O V-2$}

Since the early time of SARS-CoV-2 pandemic, two types of molecular tests were employed. Reverse transcription polymerase chain reaction (RT-PCR), the current gold standard test for covid-19 and the loop-mediated isothermal amplification (LAMP), a simple but less validated diagnostic method (Arena et al., 2021). Both amplify viral RNA but differ in the way of the viral detection. RT-PCR is wide available, fast, sensitive and a reliable technique. The technique is available as commercial complete kits (i. e. RNA extraction and Mastermix) from different companies. The assay involves converting the extracted viral RNA from the biological sample into DNA (cDNA) which then amplifies to a level which allows viral detection using designed primers targeting specific regions in the viral genome and TaqMan probes with the reaction mix in a variety of real time PCR machines. These machines allow monitoring amplification kinetic directly during the amplification run. These can be achieved by demonstrating the increase of the florescence emission intensity originated from cleavage of the fluorophore quencher probe on the amplified DNA when reaching specific threshold (Islam and Iqbal, 2020). The number of RNA copies amplified by PCR is exponentially proportional to the starting amount of viral RNA load in the sample and can be estimated via the number of PCR cycles required for fluorescent threshold (cycle threshold Ct) (Afzal, 2020). Lower Ct value means the viral RNA load (the starting material) is high. For diagnosis of SARS-CoV-2, it has been recommended that a Ct value below $37(<37)$ should be judged as clinically positive and $\mathrm{Ct}$ value above $40(>40)$ should be judged as clinically negative, while $\mathrm{Ct}$ between 37 and 40 (37 and <40) considered as indeterminant and the test required to be repeated (Afzal, 2020, Li et al., 2020). Although, the technique is highly sensitive and can detect a few copies of viral RNA in a range of laboratory samples, it is rather highly expensive, needs a well-equipped laboratory and well-trained technicians for sampling processing. Moreover, the technique takes some time (3-6hrs) to deliver the results thus cannot curb the growing corona virus testing demands and serving the waiting queues to be tested during pandemic. Therefore, it is essential to develop rapid, inexpensive and reliable diagnostic methods (Islam and Iqbal, 2020).

Loop-mediated Isothermal Amplification (LAMP) is a method by which the viral RNA is converted into viral DNA and amplified using 4- 6 designed primers targeting certain regions on the viral RNA. The technique can be done in simpler equipment, or it can be done without any equipment at all and can be conducted at a constant temperature usually between $60^{\circ} \mathrm{C}$ and $65^{\circ} \mathrm{C}$ thus minimize the time reaction to less than half an hour. The results can be seen by naked eye as a cloudiness that can be enhanced using fluorescent based detection or colorimetric based detection such as hydroxynepthol blue (HNB) in the reaction mixture prior to amplification. The technique is simple and produce 100-fold higher sensitivity than RT-PCR. The technique was further enhanced by combining the LAMP with reverse transcription (RT-LAMP) for direct detection of SARS-CoV-2 RNA coupled with a $\mathrm{pH}$ indicator to visualized the colour change in the reaction $\operatorname{mix}$ or bioluminescent indicator and smartphone (Song et al., 2018). RT-LAMP successfully detected SARS-COV-2 RNA and showed 88.89\% sensitivity and higher reproducibility than RT-PCR technique (Yu et al., 2020). Some RT-LAMP based detection kits have received EUA from FDA such as the Sherlock TM CRISPR SARS-CoV-2 kit developed by sherlock Biosciences, Inc which is designed to target ORF1ab, N, and RP genes (Yüce et al., 2021). Similarly, Abbott ID NOW COVID-19" test 
kit for SARS-COV-2 detection using LAMP principles has granted FDA emergency use authorization for fastest available molecular point-of-care test for novel coronavirus. The test could successfully preform 50,000 tests per day and the result of each sample could be obtained in 5 min (Abbott, 2020). Other approaches on the use of LAMP technique are reported. An approach carried out by EL-Tholoth et al (2020) so called COVID-19 Penn-RAMP strategy that combine LAMP and Recombinase Polymerase Amplification (RPA) in a single tube. COVID-19 PennRAMP strategy involved two isothermal amplification processes. In the first step the outer bAMP primer binds to the target sequence and amplify all targets using recombinase polymerase at $38 \mathrm{C}$ for $15-20$ min while in the second is achieved through the use of four other RAMP primers incubated at $63 \mathrm{C}$ for $40 \mathrm{~min}$ (El-Tholoth et al., 2020). A combination of reverse transcription loop-mediated amplification (RT-LAMP), Clustered Regularly Interspaced Short Palindromic Repeats (CRISPR) with lateral flow type assays (LFA) in one assay has been also reported by a group of scientists from Mammoth Biosciences Inc., University of California, Abbott Viral Diagnostics and Discovery Inc. and Centre California Department of Public Health. This combination so named "SARS-CoV-2 DETECTR" (SARS-CoV-2 DNA EndonucleaseTargeted CRISPR Trans Reporter) involved amplification of extracted Viral RNA using RT-LAMP for 20 min at $62^{\circ} \mathrm{C}$ targeting $\mathrm{E}, \mathrm{N}$, and RNAse P genes to increase the genomic copy numbers. The detection of the genomic RNA then achieved through CRISPRCas12-based detection at $37{ }^{\circ} \mathrm{C}$ for $10 \mathrm{~min}$. The CRISPR-Cas12 is a molecular scissor that employ simple, cheaper, and precise to cut the genomic DNA, in this case the reverse DNA (cDNA) and then with the help of Cas 12 guid RNAs (gRNAs), the enzyme Cas 12 will recognise the target sequence on the SARS-CoV-2 virus. Upon recognition of the matching specific target sequence, the Cas-gRNA complex cleaves the combined reporter molecule which fluorescent and visualised on a lateral flow strep as a target capture line. The whole SARS-CoV-2 DETECTR assay takes around 30-40 min (Broughton et al., 2020). This assay was then tested on 11 extracted RNA respiratory swab samples proved to be PCRpositive with COVID-19 infection and 12 swab samples from patients with influenza virus and noncovid-19 commonly human seasonal corona viruses. The SARS-CoV-2 DETECTR assay was able to detect SARS-CoV- 2 in 9 out of 11 patients swab with no cross reaction with other respiratory viruses. The sensitivity and specificity agreement of SARS-CoV-2 DETECTR relative to the CDC qRT-PCR assay were $95 \%$ and $100 \%$, respectively. This group of scientists is focusing on clinical validating of this assay to be able to receive a EUA from the FDA. They hope for the development of portable microfluidic-based cartridges and lyophilized reagents to run the assay as point-of-care testing outside the diagnostic laboratory (Broughton et al., 2020).

\section{Analytic sensitivity and diagnostic accuracy of RT-PCR assays}

Many PCR tests were developed early in the outbreak when the virus was first identified and sequenced (Khan and Cheung, 2020b, Khan and Cheung, 2020a). The US Food and Drug Administration (FDA) has granted Emergency Use Authorizations (EUAs) to commercial test manufacturers and issued guidance on test validation (FAD, 2020). Some of these protocols were published by WHO, while some were designed and adapted locally 'in house'. These resulted in potential preanalytical and analytical weaknesses. The most important criterion for successful commercial molecular assay is being of high analytic sensitivity and to have lower load of detection (LoD) to avoid false negative results and accurately diagnose SARSCOV-2 at an early stage of infection (Afzal, 2020).

The efficiency of seven commercial RT-PCR diagnostic kits for COVID-19 was compared by van Kasteren et al., (2020) and examined by 10 -fold serial dilutions of viral RNA obtained from cell culture using the MagNA Pure LC Total Nucleic Acid Isolation Kit (Roche). All assays showed an efficiency $\geq 96 \%$ and R squares of $<0.97$, which was above the pre-defined required level. The limit of detection (LOD) between the kits included in the study was determined. The lowest LOD95 was obtained at 3.8 copies $/ \mathrm{mL}$. However, in the actual clinical samples, the copy number and the limit of detection may vary according to the amount of mRNA present in the sample. This is not a problem if the assay is intended to be used for routine diagnostics of symptomatic COVID-19 patients. However, extensive clinical validations are required when adapting in-house RT-PCR kit particularly if the assay is intended to be used in a population with mild or asymptomatic patients or during the later stage of infection where a low viral load is expected (van Kasteren et al., 2020). However, even if the RT-PCR test is extremely accurate, false positive and false negative results can occur. The false positive results for SARS-CoV-2 PCR tests may be less affected than false negative. Tested positive patients whether they are true or false, required to be isolated and monitored. Contacts isolated and tested for possible infection while wrongly interpreted positive cases as negative will result in bad consequences. Infected individual allowed to return to their workplace society and infect the entire contacts.

Fortunately, Positive PCR results of covid-19 are highly trusted. The availability of covid 19 genome sequence (GenBank: MN908947) allows specific primers design and setting standard operating procedures for coronavirus 2 genomic detection (Yuan et al., 2020). The target genes for SARS-CoV-2 
RT-PCR assays may include, ORF1a, ORF1b (open reading frames a \& b), $\mathrm{S}$ (spike) gene, $\mathrm{N}$ (Nucleocapsid) gene, and the $\mathrm{M}$ (membrane) gene, all which have varied analytic sensitivity. To improve the analytic sensitivity of the PCR assays, many commercial and "in-house" PCR assays designed to detect simultaneously more than one region of the viral genome (Hu et al., 2020).

The sensitivity of the available RT-PCR tests is varied with a high chance of getting false negative results thus difficult to rule out the disease (Watson et al., 2020). The false negative may arise in many conditions such as when the viral load being below the limit of detection, poor sample quality, samples were taken too early or too late in the course of the disease, and improper sample collection and transportation. Another very significant influence that may lead to underperformance of RT-PCR contributing to false negative SARS-CoV-2 test results is the affinity of SARS-CoV-2 genome to mutate. Due to the rapid spread of the virus, early diagnostic tool was very demanding for control and prevention of the disease. Given the affinity of the viral genome to mutate, the genetic variation at the primer and probe region may cause mismatched and false negative results. A study by Khan and Cheung (2020) for reassessment of 27 published covid-19 diagnostic PCR assays reported the presence of mismatches in primer and probe binding regions of 7 assays. The authors pointed out the importance of re-evaluation of the adapted PCR assays periodically to ensure their accuracy and reduce the false negative results (Khan and Cheung, 2020b).

\section{Optimizing test performance: sensitivity, specificity, PPV and NPV of RT-PCR assays}

The basic aim of any diagnostic test is to provide a clinician a thought whether a patient has a particular disease or not, for proper clinical decision making and good management strategy. Therefore, we need to be confident about the performance of a new diagnostic test. A new diagnostic test should be validated against what is called gold standard. A gold standard test is a common acceptable available test (Rajul Parikh et al., 2008). For example, a gold standard test for molecular detection of blood stream infection is the blood culture. Validation of a new diagnostic test is measured by sensitivity and specificity. Sensitivity is a probability of a tested positive among diseased patients while specificity is a probability of a tested negative among nondiseased patients.

As SARS-CoV-2 is a new immerged disease. There is no previously available gold standard test. Scientist have grown the virus in a tissue culture, determine the efficiency of the PCR assays by examining serial dilutions of known amount of viral RNA copies to determine the limit of detection of these assays. Further the sensitivity and the specificity of the test could be determined by examining known positive or negative samples against unknown samples (van Kasteren et al., 2020). These two values are fixed once determined experimentally for a particular test and a particular sample size but are not enough for interpretation of a negative or positive result and cannot be used as a guidance for decision making for the management of the disease (Richter, 2020). The positive and negative results should be interpreted in the light of how likely the patients have the disease before achieving the test. This is what is called prediction values. Positive Predictive value (PPV) is the percentage of patients with a positive test who have the disease. Negative Predictive Value (NPV) is the percentage of patients with a negative test who do not have the disease. Unlike to sensitivity and specificity, these two values are affected by the prevalence of the disease in the place of testing. A negative predictive test decreases with increasing prevalence. Therefore, negative tested patients in high prevalence area should be isolated until resolution of symptoms and their negative results should be interpreted with caution with repeated testing if necessary (Kokkinakis et al., 2020).

\section{Specimen Collection and Infectivity of the virus during the clinical course of the disease}

Samples collected should be stored directly at 2$8^{\circ} \mathrm{C}$ and shipped on ice packs to the laboratory within $72 \mathrm{hrs}$. If testing of the samples were delayed under any circumstance, specimens should be frozen at $70^{\circ} \mathrm{C}$ (CDC, 2020). The collected clinical specimen should be added to the lysis buffer as soon as possible to disinfect the specimens and reduce degradation of the genomic RNA (Chan et al., 2004).

Samples can be collected from different locations. However, it is difficult to speculate how well different samples will perform against each other (Andrea. Prinzi, 2020). Most studies have shown that pneumonia is the common complication of covid-19, thus, collecting specimens from the lower respiratory tract would be the optimum source of sampling. However, collection from the lower respiratory tract (Bronchial lavage BAL) required highly skilled person, in addition it is painful for the patient, consequently it is not feasible for routine laboratory diagnosis. In contrast nasopharyngeal, throat and sputum are rapid, simple and safe to collect (Yang et al., 2020). A study by yang et al (2020) on 213 revealed that infected patient's sputum possess the highest positive rate followed by nasal swab during the first 14 days of the onset of symptoms while viral RNA can be detected in BAL in the sever cases ( $\geq 15$ days) but not in mild cases (Yang et al., 2020). Similar results obtained by wolfel et al (2020) who suggested that active pharyngeal viruses are shedding at a time when the patients reveal mild symptoms, while later in the course of the 
disease replication in the lower respiratory tract is more predominant (Wölfel et al., 2020). However, SARS-CoV-2 virus does not typically produce purulent sputum. Therefore, nasopharyngeal would be the method of choice for specimen collection (Loeffelholz and Tang, 2020). Fecal samples have gained huge concern in particular for confirming recovered patients, thus reducing recurrent infection (Ling et al., 2020). In a study by Xu et al. (2020), 8 out of 10 children tested positive on rectal swab although the nasopharyngeal swab tested negative. The authors emphasised the importance of rectal sample for monitoring discharge patients (Xu et al., 2020).

The timing of sampling during the course of the disease is very important to reduce the false negative results. Viral load may be below the limit of detection if the sample was taken too early or too late in the course of the disease as the virus shedding would be too little to be detected. As the virus is not typical, there was a wide difference in the time line on how long the onset of symptoms show up after exposure (Wölfel et al., 2020). Some people start to show up symptoms shortly after infection and other may experience symptoms after two weeks of exposure (Annie Vainshtein, 2020). In general, viral shedding would be longer in severe cases (Yang et al., 2020). However, the patients with a history of exposure may show up positive RT-PCR results before becoming symptomatic (Pan et al., 2020). Kucirka, and colleagues (2020) reviewed and studied 7 published studies to estimate the false negative rate day by day since the infection. They suggested that the probability of a false-negative result in an infected person decreases from $100 \%$ on day 1 to $67 \%$ on day 4 , just one day before the onset of symptom. On day 5 the false-negative rate was $38 \%$ which decreased to $20 \%$ by day 8 ( 3 days after symptom onset) then start to increase again, reaching to $66 \%$ on day 21 . The study recommended careful interpretation of RT-PCR results in the course of infection and advice the clinicians to wait 1 to 3 days after symptom onset before sampling to minimize the probability of a false negative result (Kucirka et al.). However, patients with a history of exposure may show up positive RTPCR results before becoming symptomatic (Pan et al., 2020). Viral shedding may peak on or before symptoms onset of SARS-CoV-2 confirmed patients (He et al., 2020). Therefore, in highly suspected patients, PCR testing should be repeated to minimise the false negative results because the probability of the virus to be present will rise over the time (Loeffelholz and Tang, 2020).

\section{Viral RNA load in the samples}

Viral load should be above the limit of detection for satisfying results of PCR assays. If the viral load was below the limit of detection, then, unspecific amplification signal may be initiated, and false positive results may occur at high cycle threshold (Ct) value (i. e. Ct $>38$ depends on the laboratory developed assay). High cycle threshold results should be reported as indeterminant results and the test is required to be repeated and further investigation using another well validated PCR assay or nucleic acid sequencing assay should be considered (PHO, 2020). Although low Ct value may indicate higher viral load and high transmissibility of the virus, the viral load should not be used to indicate the severity of the virus or to monitor the response to the treatment (Tang et al., 2020).

The amount of the viral RNA load in the sample may be reduced with the type of extraction kits and the amount of the viral RNA taken onto the Mastermix for amplification. Moreover, it has been reported that the heat inactivation step incorporated with some extraction kits have reduced the amount of starting genomic viral RNA (Yan et al., 2020). Inactivation of the virus should be achieved without reducing the detection efficiency. Ideally, a standard methodological step has been used for years. These include incorporation of Trizol (life technology) and buffer AVL from Qiagen to the extraction process for inactivation, extraction and purifying the viral RNA. The guanidine salt in thi⿺ buffer inhibits the nuclease thus ensuring viral RNA integrity and not degraded up to 35 days under -20 c storage condition (Burton et al., 2017).

\section{Effect of ongoing SARS-CoV-2 genetic variability on performance of $R T$-PCR}

Since emerging of COVID-19 pandemic, the SARS-CoV-2 genome has accumulated considerable amount of genetic variability and recurrent mutation. According to available data, the rate of genomic variability is approximately $9.8 \times 10^{-4}$ substitutions per site per year (van Dorp et al., 2020). This genomic variation has enabled classification efforts by Nextstrain and GISAID to allocates nomenclature to the SARSCoV-2 clades into several well-defined clades according to the frequency of geographic spread and the statistical distribution of genome distance using Phylogenetic Clustering by Linear Integer Programming (PhyCLIP) respectively (Han et al., 2019). According to GISAID calcifications, the first isolate appeared in Wuhan in the late 2019 was assigned the $\mathrm{L}$ clad, $\mathrm{S}$ clade for the variant appeared in the beginning of 2020 and then $\mathrm{V}$ and $\mathrm{G}$ clades become prevalent by mid-January followed by GR and GH by the end of February and GV later. While G, GH and GR are constantly increasing globally, S, L, and V strains are gradually waning (Mercatelli and Giorgi, 2020). Recently, three SARS-CoV-2 variants of concern have been reported. The UK lineage B.1.1.7 reported in November 2020 and started to spread quickly by mid-December 2020 causing significant increase in SARS-CoV-2 infections in the country. The increase in the transmissibility is believed to be due to unusual large number of genetic mutations of the 
spike protein. This mutation is also reported in another lineage assigned B.1.1351/variant 501Y.V2, that was identified in South Africa and widespread all over the world. The third one which is probably the most concerned mutation is the lineage B.1.1.28 which evolved in two independents Brazilian regions, the state of Rio de Janeiro and Manaus amazon state. These are the P.2, the lineage of SARS-CoV-2, originated from B.1.1.28, reported from 180 sequenced samples obtained from different municipalities in the state of Rio de Janeiro from April to December 2020 and was distinguished by five lineage-defining mutations (C100U/ C28253U/ G28628U/ G28975U/ C29754U) (Voloch et al., 2020) , and P.1, the lineage of SARS-CoV-2, originated from B.1.1.28, designated as B.1.1.28 (K417N/E484K/N501Y) recently detected in Japanese travellers returning from Amazonas. Phylogenetic analysis of 148 SARS-CoV-2 wholegenome viral sequences from Amazon state in Brazil between April and November 2020 ensured the original emerging of Brazilian lineage. At least, three of SARS-CoV-2 lineages (B.1.1.33, P.1,P.2) harbour the E484K mutation that are associated with escape from neutralizing antibodies (Nonaka et al., 2021).

Several studies have evaluated the impact of mutation in the SARS-CoV-2 genome regions of interest, thus the ability of available sets of primers and probes for correctly identification the virus in the clinical samples. Khan and Cheung (2020) evaluated 17,000 viral sequences from all over the world. They reported moderate mismatched in primer/probe binding regions of 7 assays out of 27 assays studied, the region of the viral sequence targeted by the Charité-ORF1b primer and the region of the China CDC forward $\mathrm{N}$ gene primer. In the largest study belonging to bioinformatic project, nine different published primers and probes sets were analysed by Peñarrubia L. et al. with more than 30,000 SARS-CoV2 viral sequences. They reported that a around 34\% of the studied genomes have encountered mutations in the regions of interest of various primers. The authors suggested that adapting multiplexing methods will alleviate the risk of reduction in RT-PCR sensitivity (Peñarrubia et al., 2020). The analytic study has been expanded by Arena et.al (2021) to involve a selection of more resent genomic sequences among the GISAID interactive database to examine the genomic variability in the WHO RT-PCR primers/probes regions of interest. The authors found that the majority of primer/ probe binding regions exhibit no mutation or mismatch while the nucleotide variations was mainly belonging to GR and $\mathrm{GH}$ clades found among recently sequenced genomes from Europe and North America. The study further expanded to involve a representative genome belonging to the B.1.1.7 variant and the South Africa 501Y.V2 variant for the presence of mismatches in regions of interest of the WHO RT-PCR primers/probes sets. The analysis revealed a perfect match between primers/probes released by WHO and the genome sequence of the B.1.1.7 variant with the exception of the mismatch presented in the first three positions of the China CDC $\mathrm{N}$ forward primer (AAC variant) and two mismatched of the genome sequence of the South Africa 501Y.V2 variant, the central parts of China CDC $\mathrm{N}$ forward primer and the Japan National Institute of Infectious Diseases $\mathrm{N}$ reverse primer (Arena et al., 2021). The authors concluded that the described genetic variability including the UK B 1.1.7 and the South Africa 501Y.V2 variants, have minimal or no effect on the sensitivity of the existence PCR methods for SARS-CoV-2 genome detection and that the genomic variability should be considered when a new diagnostic test is released and for ideally results multiple targets are favoured to increase detection sensitivity (Arena et al., 2021).

\section{Recurrent infection and test of cure}

Re-positive to PCR for SARS-CoV-2 after discharge of confirmed recovered cases are very common. According to the current criteria of discharge, $20 \%$ of recovered cases could become positive RT-PCR test results again (Zou et al., 2020). The majority of recurrent infected patients have shown mild or no clinical symptoms but death from the second episode have been recorded (Gousseff et al., 2020). There are several possible reasons which may explain recurrence infection among recovered patients after clinical recovery. These include, false PCR results, intermitting viral shedding, reactivation of the virus and newly infection from other patients (Dao et al., 2021). As discussed before, the reasons for false negative PCR result may include poor sampling quality, samples were taken in the wrong time, sensitivity, and specificity of the PCR kit itself. Intermitting viral shedding may also contribute to the false negative of Covid-19 RT-PCR results. In a study conducted by wang et.al (2020) on 37 discharged patients, 5 patients have shown two consecutive false negative results after clinically recovery, defined as (positive, negative, negative, positive) covid-19 PCR results. The study suggested that the viral shedding may be intermitting (Wang et al., 2020). Reactivation of the virus may also occur leading to recurrence infection. Viral reactivation was reported in an immunocompetent 33-year-old-patient was diagnosed with recurrent covid-19 infection 5 months after the first episode. Immunoglobulin G were confirmed 5 days later after second hospital admission. Reactivation of the same virus of this patient was genetically confirmed with whole genome sequencing (To et al., 2020). Re-infection with another SARS-CoV-2 strain has been also reported. Re-infection may be explained by poor building up of humoral immunity (Gao et al., 2020) or re-infection with immune escape emergence mutated 
viral strains. Alonso et. al (2021) reported a case of re-infection in 26-year-old patient 40 day after clinical recovery from the first mild infection with covid-19. The viral load and the clinical symptoms were much higher in the second infection episode. The protective antibodies were only detected in the second infection suggesting a new infection (Alonso et al., 2021). Nonaka et.al (2021) investigated a recurrent 45-year-old infected healthcare female resided in Northeast Brazil. The patient presented with two COVID-19 episodes, separated by a 147-day interval. The phylogenetic analysis of whole genome sequences revealed that the two COVID-19 episodes were a distinct SARS-CoV-2 lineage. In the first episode, the lineage B.1.1.33 was detected, whereas E484K mutation harbour P.2 lineage, the variant known to escape from neutralizing antibodies. was detected in the second infection (Nonaka et al., 2021).

Up to date, no evidence indicates infectivity of re-positive cases was found. The KCDC investigation on 285 cases reveals no newly infected cases from contacts with re-positive cases. They reported that live virus could not be isolated from cell culture of respiratory samples taken from 108 re-positive cases. According to the study, the KCDC protocol management of re-positive cases no longer conducted, 14-days self-isolation after discharge from isolation of re-positive cases is no longer recommended, the PCR test is not required even if the symptoms appeared within 14 days of discharge and no need to quarantine the contacts of re-positive cases (KCDC, 2020). However, it is still not clear whether the reinfected patients become contagious for others. Therefore, it is necessary to ensure truly negativity of the PCR results, ideally by three consecutive negative results (Zou et al., 2020), and monitoring patients during the recovery period, ideally through PCR testing of fecal sample in order to reduce the risk of reinfection and the spread of the pandemic (Ling et al., 2020). Currently, the WHO criteria for releasing COVID-19 patients from isolation without the needs for re-testing recommended 10 days after the onset of symptoms, plus additional three days without symptom in patients initially showed symptoms, and 10 days after a positive test for SARS-CoV-2 in asymptomatic patients (World Health, 2020). However, longer observation and isolation periods in particular for certain groups of patients should be considered (Dao et al., 2021) and re-evaluate of the current hospital discharge criteria and establishment of rigorous, evidence-based policies for COVID-19 prevention and control is recommended (Zou et al., 2020).

\section{Conclusion}

Based on the literature information available so far, we can conclude that a single negative RT-PCR test was insufficient to exclude SARS-CoV-2 infection. Three consecutive negative RT-PCR results should be considered as discharge criterion to minimize the repositive PCR results and face the urgent public heath crises. Currently, detection of SARS-CoV-2 viral genome are solely dependent on RT-PCR methods. However, assays using RT-PCR approaches are expensive, need special equipment and expertise, given the turn-around time for diagnosing patients and samples shipping, the time may extend to over 24 hrs. Loop-mediated approaches on the other hand could deliver rapid and accurate results with compromising sensitivity and specificity and are proving to be promising technology to be used as point of care testing to face the increased need of patients screening and monitoring.

Re-positive PCR results for recovered SARSCoV-2 or so-called recurrent infection, could be explained either as false PCR results, intermitting viral shedding, reactivation of the virus or newly infection with newly genetically variant strains. However, according to the published data, the currently known variants should have minimum effect on the existing molecular detection methods. Continuous validation of the RT-PCR methods to ensure proper annealing of the primer and probes and incorporation of multi target gene detection (multiplexing) are very demanding for proper detection of newly emerging SARS-CoV-2 lineage mutations.

Conflict of interest: There are no conflicts of interest.

Acknowledgment: I am grateful to Mrs Shada. K. Abujaafar for her valuable contribution to deliver this manuscript.

\section{References}

1. ABBOTT. 2020. Detect COVID-19 in as Little as 5 Minutes [Online]. Available: https://www.abbott.com/corpnewsroom/diagnosticstesting/detect-covid-19-in-as-little-as-5-minutes.html [Accessed].

2. AFZAL, A. (2020). Molecular diagnostic technologies for COVID-19: Limitations and challenges. J Adv Res., 26: 149-159, https://doi.org/10.1016/j.jare.2020.08.002.

3. ALONSO, F. O. M., SABINO, B. D., GUIMARÃES, M. A. A. M. \& VARELLA, R. B. (2021). Recurrence of SARS-CoV2 infection with a more severe case after mild COVID19, reversion of RT-qPCR for positive and late antibody response: Case report. Journal of Medical Virology, 93(2): 655-656, https://doi.org/10.1002/jmv.26432.

4. ANDREA. PRINZI (2020). False Negatives and Reinfections: the Challenges of SARS-CoV-2 RT-PCR Testing. American Society For Microbiology.

5. ANNIE VAINSHTEIN. (2020). Why some people get coronavirus symptoms, but still test negative [Online]. Available: https://www.sfchronicle.com/bayarea/article/Why-somepeople-get-coronavirus-symptoms-but-15342542.php [Accessed]. 
6. ARENA, F., POLlini, S., ROSSOLINI, G. M. \& MARGAGLIONE, M. (2021). Summary of the Available Molecular Methods for Detection of SARS-CoV-2 during the Ongoing Pandemic. International Journal of Molecular Sciences, 22(3): 1298, https://doi.org/10.3390/ijms22031298.

7. BROUGHTON, J. P., DENG, X., YU, G., FASCHING, C. L., SERVELLITA, V., SINGH, J., et al. (2020). CRISPRCas12-based detection of SARS-CoV-2. Nature Biotechnology, 38: 870-874.

8. BURTON, J. E., EASTERBROOK, L. \& PITMAN, J. (2017). The effect of a nondenaturing detergent and a guanidinium-based inactivation agent on the viability of Ebola virus in mock clinical serum samples. Virol Methods., 250: 34-40, https://doi.org/10.1016/j.jviromet.2017.09.020.

9. CDC. (2020). Interim Guidelines for Collecting, Handling, and Testing Clinical Specimens From Persons for Coronavirus Disease 2019 (COVID-19). Available: $\quad$ https://www.cdc.gov/coronavirus/2019$\mathrm{nCoV} / \mathrm{lab} /$ guidelines-clinical-specimens.html [Accessed March 3, 2021].

10. CHAN, P. K., TO, W., NG, K., LAM, R. K., NG, T., CHAN, R. C., et al. (2004). Laboratory Diagnosis of SARS. Emerging Infectious Diseases. Emerg Infect Dis, 10: 825-831.

11. DAO, T. L., HOANG, V. T. \& GAUTRET, P. (2021). Recurrence of SARS-CoV-2 viral RNA in recovered COVID-19 patients: a narrative review. Eur J Clin Microbiol Infect Dis, 40(1): 13-25, https://doi.org/10.1007/s10096-020-04088-z

12. EL-THOLOTH, M., BAU, H. H. \& SONG, J. (2020). $A$ Single and Two-Stage, Closed-Tube, Molecular Test for the 2019 Novel Coronavirus (COVID-19) at Home, Clinic, and Points of Entry. Available: https://doi.org/10.26434/chemrxiv.11860137.v1

13. FAD. (2020). Emergency Use Authorization (EUA) information, and list of all current EUAs. Available: https://www.fda.gov/emergency-preparedness-andresponse/mcm-legal-regulatory-and-policyframework/emergency-use-authorization.

14. GAO, Z., XU, Y., GUO, Y., XU, D., ZHANG, L., WANG, X., et al. (2020). A systematic review of re-detectable positive virus nucleic acid among COVID-19 patients in recovery phase. Infection, Genetics and Evolution, 85: 104494, https://doi.org/10.1016/j.meegid.2020.104494.

15. GOUSSEFF, M., PENOT, P., GALLAY, L., BATISSE, D., BENECH, N., BOUILLER, K., et al. (2020). Clinical recurrences of COVID-19 symptoms after recovery: Viral relapse, reinfection or inflammatory rebound? Journal of Infection, 81(5): 816-846, https://doi.org/10.1016/j.jinf.2020.06.073.

16. HAN, A. X., PARKER, E., SCHOLER, F., MAURERSTROH, S. \& RUSSELL, C. A. (2019). Phylogenetic Clustering by Linear Integer Programming (PhyCLIP). Molecular Biology and Evolution, 36(7): 1580-1595, https://doi.org/10.1093/molbev/msz053.

17. HE, X., LAU, E. H. Y., WU, P., DENG, X., WANG, J., HAO, $X$. , et al. (2020). Temporal dynamics in viral shedding and transmissibility of COVID-19. Nature Medicine,
26(5): 672-675, https://doi.org/10.1038/s41591-0200869-5.

18. HU, T., LIU, Y., MINGYI, Z., QUAN, Z., XU, L. \& HE, Q. (2020). A comparison of COVID-19, SARS and MERS. 8.

19. ISLAM, K. U. \& IQBAL, J. (2020). An Update on Molecular Diagnostics for COVID-19. Front Cell Infect Microbiol, 10: 560616, https://doi.org/10.3389/fcimb.2020.560616.

20. KCDC. (2020). Finding from Investigation and Analysis of Re-Posative Cases. Available: https://www.cdc.go.kr/board/board.es?mid=a304020000 $00 \&$ bid $=0030$

21. KHAN, K. A. \& CHEUNG, P. (2020a). Presence of mismatches between diagnostic PCR assays and coronavirus SARS-CoV-2 genome. $R$. Soc. open sci., 7(6): 200636, https://doi.org/10.1098/rsos.200636.

22. KHAN, K. A. \& CHEUNG, P. (2020b). Presence of mismatches between diagnostic PCR assays and coronavirus SARS-CoV-2 genome. R Soc Open Sci, 7, 200636.

23. KOKKINAKIS, I., SELBY, K., FAVRAT, B., GENTON, B. \& CORNUZ, J. (2020). [Covid-19 diagnosis : clinical recommendations and performance of nasopharyngeal swab-PCR]. Rev Med Suisse, 16: 699701.

24. KUCIRKA, L. M., LAUER, S. A., LAEYENDECKER, O., BOON, D. \& LESSLER, J. (2020). Variation in FalseNegative Rate of Reverse Transcriptase Polymerase Chain Reaction-Based SARS-CoV-2 Tests by Time Since Exposure. Annals of Internal Medicine, 173(4): 262 - 267, https://doi.org/10.7326/m20-1495.

25. LI, Q., GUAN, X., WU, P., WANG, X., ZHOU, L., TONG, Y., et al. (2020). Early Transmission Dynamics in Wuhan, China, of Novel Coronavirus-Infected Pneumonia. New England Journal of Medicine, 382: 1199-1207.

26. LING, Y., XU, S.-B., LIN, Y.-X., TIAN, D., ZHU, Z.-Q., DAI, F.-H., et al. (2020). Persistence and clearance of viral RNA in 2019 novel coronavirus disease rehabilitation patients. Chinese Medical Journal, 133(9): 10391043, https://doi.org/10.1097/cm9.0000000000000774.

27. LOEFFELHOLZ, M. J. \& TANG, Y. W. (2020). Laboratory diagnosis of emerging human coronavirus infections - the state of the art. Emerg Microbes Infect, 9(1): 747-756, https://doi.org/10.1080/22221751.2020.1745095.

28. MANSKI, C. F. (2020). Bounding the Predictive Values of COVID-19 Antibody Tests. medRxiv, 2020.05.14.20102061.

29. MERCATELLI, D. \& GIORGI, F. M. (2020). Geographic and Genomic Distribution of SARS-CoV-2 Mutations. Frontiers in Microbiology, 11, https://doi.org/10.3389/fmicb.2020.01800.

30. NONAKA, C. K. V., FRANCO, M. M., GRÄF, T., DE LORENZO BARCIA, C. A., DE ÁVILA MENDONÇA, R. N., DE SOUSA, K. A. F., et al. (2021). Genomic Evidence of SARS-CoV-2 Reinfection Involving E484K Spike Mutation, Brazil. Emerg Infect Dis, 27(5): 1522 - 1524, https://doi.org/10.3201/eid2705.210191. 
31. PAN, Y., ZHANG, D., YANG, P., POON, L. L. M. \& WANG, Q. (2020). Viral load of SARS-CoV-2 in clinical samples. The Lancet. Infectious diseases, 20(4): 411412, https://doi.org/10.1016/s1473-3099(20)30113-4.

32. PEÑARRUBIA, L., RUIZ, M., PORCO, R., RAO, S. N., JUANOLA-FALGARONA, M., MANISSERO, D., et al. (2020). Multiple assays in a real-time RT-PCR SARSCoV-2 panel can mitigate the risk of loss of sensitivity by new genomic variants during the COVID-19 outbreak. International Journal of Infectious Diseases, 97: 225-229, https://doi.org/10.1016/j.ijid.2020.06.027.

33. PFEFFERLE, S., REUCHER, S., NÖRZ, D. \& LÜTGEHETMANN, M. (2020). Evaluation of a quantitative RT-PCR assay for the detection of the emerging coronavirus SARS-CoV-2 using a high throughput system. Euro surveillance : bulletin Europeen surles maladies transmissibles $=$ European communicable disease bulletin, 25: 2000152.

34. PHO. (2020). Coronavirus Disease 2019 (COVID-19)PCR. Available:

https://www.publichealthontario.ca/en/laboratoryservices/test-information-index/covid-19.

35. RAJUL PARIKH, ANNIE MATHAI, SHEFALI PARIKH, G CHANDRA SEKHAR \& RAVI THOMAS (2008). Understanding and using sensitivity, specificity and predictive values. Indian J Ophthalmol., 56(1): 45-50, https://doi.org/10.4103/0301-4738.37595.

36. RICHTER, S. M. (2020). Specificity, positive predictive value and validation statistics in the context of CoViD19.

37. SONG, J., PANDIAN, V., MAUK, M. G., BAU, H. H., CHERRY, S., TISI, L. C., et al. (2018). SmartphoneBased Mobile Detection Platform for Molecular Diagnostics and Spatiotemporal Disease Mapping. Analytical Chemistry, 90(7): 4823-4831, https://doi.org/10.1021/acs.analchem.8b00283.

38. TANG, Y. W., SCHMITZ, J. E., PERSING, D. H. \& STRATTON, C. W. (2020). Laboratory Diagnosis of COVID-19: Current Issues and Challenges. I Clin Microbiol, 58(6), https://doi.org/10.1128/jcm.00512-20.

39. TO, K. K.-W., HUNG, I. F.-N., IP, J. D., CHU, A. W.-H., CHAN, W.-M., TAM, A. R., et al. (2020). Coronavirus Disease 2019 (COVID-19) Re-infection by a Phylogenetically Distinct Severe Acute Respiratory Syndrome Coronavirus 2 Strain Confirmed by Whole Genome Sequencing. Clinical Infectious Diseases, https://doi.org/10.1093/cid/ciaa1275.

40. VAN DORP, L., ACMAN, M., RICHARD, D., SHAW, L. P., FORD, C. E., ORMOND, L., et al. (2020). Emergence of genomic diversity and recurrent mutations in SARSCoV-2. Infection, Genetics and Evolution, 83: 104351, https://doi.org/10.1016/j.meegid.2020.104351.

41. VAN KASTEREN, P. B., VAN DER VEER, B., VAN DEN BRINK, S., WIJSMAN, L., DE JONGE, J., VAN DEN BRANDT, A., et al. (2020). Comparison of seven commercial RT-PCR diagnostic kits for COVID-19. Journal of Clinical Virology, 128: 104412, https://doi.org/10.1016/j.jcv.2020.104412.
42. VOLOCH, C. M., SILVA F, R. D., DE ALMEIDA, L. G. P., CARDOSO, C. C., BRUSTOLINI, O. J., GERBER, A. L., et al. (2020). Genomic characterization of a novel SARSCoV-2 lineage from Rio de Janeiro, Brazil. medRxiv, 2020.12.23.20248598.

43. WANG, G., YU, N., XIAO, W., ZHAO, C. \& WANG, Z. (2020). Consecutive false-negative rRT-PCR test results for SARS-CoV-2 in patients after clinical recovery from COVID-19. Journal of Medical Virology, 92(11): 2887-2890, https://doi.org/10.1002/jmv.26192.

44. WATSON, J., WHITING, P. F. \& BRUSH, J. E. (2020). Interpreting a covid-19 test result. BMJ, 369: m1808, https://doi.org/10.1136/bmj.m1808.

45. WÖLFEL, R., CORMAN, V. M., GUGGEMOS, W., SEILMAIER, M., ZANGE, S., MÜLLER, M. A., et al. (2020). Virological assessment of hospitalized patients with COVID-2019. Nature, 581: 465-469.

46. WORLD HEALTH, 0. (2020). Criteria for releasing COVID-19 patients from isolation: scientific brief, 17 June 2020. Geneva: World Health Organization.

47. XU, Y., LI, X., ZHU, B., LIANG, H., FANG, C., GONG, Y., et al. (2020). Characteristics of pediatric SARS-CoV-2 infection and potential evidence for persistent fecal viral shedding. Nature Medicine, 26(4): 502-505, https://doi.org/10.1038/s41591-020-0817-4.

48. YAN, Y., CHANG, L. \& WANG, L. (2020). Laboratory testing of SARS-CoV, MERS-CoV, and SARS-CoV-2 (2019-nCoV): Current status, challenges, and countermeasures. Rev Med Virol, 30 (3): e2106, https://doi.org/10.1002/rmv.2106.

49. YANG, Y., YANG, M., SHEN, C., WANG, F., YUAN, J., LI, J., et al. (2020). Evaluating the accuracy of different respiratory specimens in the laboratory diagnosis and monitoring the viral shedding of $2019-\mathrm{nCoV}$ infections. medRxiv, 2020.02.11.20021493.

50. YU, L., WU, S., HAO, X., DONG, X., MAO, L., PELECHANO, V., et al. (2020). Rapid Detection of COVID-19 Coronavirus Using a Reverse Transcriptional LoopMediated Isothermal Amplification (RT-LAMP) Diagnostic Platform. Clinical Chemistry, 66(7): 975977, https://doi.org/10.1093/clinchem/hvaa102.

51. YUAN, X., YANG, C., HE, Q., CHEN, J., YU, D., LI, J., et al. (2020). Current and Perspective Diagnostic Techniques for COVID-19. ACS Infectious Diseases, 6 (8): 1998-2016, https://doi.org/10.1021/acsinfecdis.0c00365.

52. YÜCE, M., FILIZTEKIN, E. \& ÖZKAYA, K. G. (2021). COVID-19 diagnosis -A review of current methods. Biosens Bioelectron, 172: 112752, https://doi.org/10.1016/j.bios.2020.112752.

53. ZOU, Y., WANG, B.-R., SUN, L., XU, S., KONG, Y.-G., SHEN, L.-I., et al. (2020). The Issue of Recurrently Positive Patients Who Recovered From COVID-19 According to the Current Discharge Criteria: Investigation of Patients from Multiple Medical Institutions in Wuhan, China. The Journal of Infectious Diseases, 222(11): 1784-1788, https://doi.org/10.1093/infdis/jiaa301. 